\title{
Depressive symptoms in Type 1 and Type 2 Diabetes Mellitus and its relationship with glycemic control
}

\author{
Sintomas depressivos em pacientes com Diabetes Mellitus Tipo 1 e Tipo 2 e \\ sua relação com o controlo glicémico
}

\author{
Ilda Massano-Cardoso $(1,2,3)$ \\ Fernanda Daniel $(1,3)$ \\ Vítor Rodrigues (2) \\ Ana Galhardo (1,4) \\ (1) Inst Sup Miguel Torga, Coimbra, Portugal \\ (2) Univ Coimbra, FMUC, Portugal \\ (3) Univ Coimbra, CEISUC, FEUC, Portugal \\ (4) Univ Coimbra, CINEICC, FPCEUC, Portugal
}

Recebido: 07/02/2020; Revisto: 13/03/2020; Aceite: 24/04/2020.

\begin{abstract}
Objective: The current study assessed depressive symptoms in Type 1 Diabetes Mellitus (T1DM) and Type 2 Diabetes Mellitus (T2DM) patients and explored whether these symptoms were associated with glycemic control. Methods: A cross-sectional design was used. Patients attending diabetes consultations participated in the study $(N=347)$. Participants completed the Beck Depression Inventory (BDI), and glycemic control was based on A1C criteria. Results: The mean score on the BDI, for either T1DM or T2DM, was not clinically significant and was not associated with diagnosis duration. The association between depression and glycemic control was significant in both DM types. T2DM participants presenting more depressive symptoms were those with greater glycemic control. T1DM and T2DM differences regarding depressive symptoms were in somatic symptoms. Conclusions: In T2DM depressive symptoms may be confounded with DM physical consequences. There is also the possibility that negative mood plays a mediating role in mobilizing survival strategies that promote glycemic control. Furthermore, the assessment of depressive symptomatology in patients with diabetes could benefit from the availability of a disease-specific measure.
\end{abstract}

Keywords: Diabetes mellitus; Type 1 diabetes; Type 2 diabetes; Depressive symptoms; Glycemic control.

\section{DI\&D | ISMT}

rpics@ismt.pt

https://rpics.ismt.pt
Publicação em Acesso Aberto

(c)2020. O(s) Autor(es). Este é um artigo de acesso aberto distribuído sob a Licença Creative Commons Attribution, que permite uso, distribuição e reprodução sem restrições em qualquer meio, desde que o trabalho original seja devidamente citado.
Ilda Massano-Cardoso Instituto Superior Miguel Torga

Largo da Cruz de Celas, n¹, 3000-132 Coimbra, Portugal e-mail: ildamassano@ismt.pt 


\section{Resumo}

Objetivo: O presente estudo procurou avaliar a presença de sintomas depressivos em pacientes com diabetes mellitus tipo 1 (T1DM) e tipo 2 (T2DM), explorando a sua associação com o controlo glicémico. Métodos: Estudo de desenho transversal. Participaram no estudo 347 pacientes com um diagnóstico de diabetes mellitus tipo 1 e tipo 2, os quais preencheram um questionário sociodemográfico e clínico e o Inventário Depressivo de Beck (BDI). Os valores do controlo glicémico foram facultados pelo clínico assistente, sendo baseados no critério de hemoglobina glicada (A1C). Resultados: O score médio do BDI total para os pacientes com T1DM ou T2DM não se revelou clinicamente significativo e não se encontrou associado à duração da doença. A associação entre sintomas depressivos e controlo glicémico foi significativa em ambos os tipos de diabetes. Os pacientes com T2DM que apresentaram mais sintomas depressivos foram os que evidenciavam maior controlo glicémico. As diferenças observadas nos sintomas depressivos dos pacientes com T1DM e T2DM manifestaram-se nos sintomas somáticos avaliados pelo BDI. Conclusões: Os sintomas depressivos nos pacientes com T2DM podem ser confundidos com as consequências físicas da própria diabetes. De referir igualmente a possibilidade de o humor negativo desempenhar um papel mediador na mobilização das estratégias promotoras de um adequado controlo glicémico.

Palavras-Chave: Diabetes mellitus; Diabetes tipo 1; Diabetes tipo 2; Sintomas depressivos; Controlo glicémico.

\section{Introduction}

Diabetes mellitus (DM) integrates a heterogeneous group of metabolic disorders characterized by the body's inability to maintain glucose homeostasis. In 2019, this public health problem affected 463 million adults, and this will rise to 700 million in 2045 (International Diabetes Federation, 2020). Furthermore, 30\% to 80\% of cases remain undiagnosed, this being a major challenge in public health (World Health Organization [WHO], 2011). Type 2 DM (T2DM) is the most common, being responsible for 95\% or more of the total cases. It is closely associated with lifestyle factors (e.g., diet and physical activity levels). T2DM is has a higher prevalence among middle-aged and older individuals, although it is increasingly appearing in overweight children, adolescents, and young adults (WHO, 2016). T1DM is less prevalent (3-5\% of all cases of DM) and affects children and young adults, particularly. T1DM is characterized by the pancreatic beta-cell mass destruction, being these cells responsible for producing insulin. Although not fully understood, the origin of T1DM seems to be related to an overaggressive autoimmune response, which leads to the failure of pancreatic endocrine function (Kahanovitz et al., 2017).

There is consensus in the fact that that depression is commonly associated with chronic illnesses (e.g., Gonzalez et al., 2007; Park et al., 2004). Depression tends to appear as a comorbid condition in patients suffering from chronic diseases, as in the case of DM (Chireh \& D'Arcy, 2019). It is common to observe an increase in symptomatology and medical costs, a decline in adherence to prescribed therapies, as well as a greater risk of morbidity and mortality (Son et al., 2011), specifically in terms of DM, a proportion of DM patients (20-40\%) experience emotional difficulties, ranging from disorders specifically related to the disease to general symptoms of anxiety and depression (Son et al., 2011). Regarding depression, it constitutes not only a risk factor for the development of DM but is also a psychiatric condition highly prevalent in DM patients (WHO, 2003). Prospective studies with representative samples (1715, 2662, and 2764 individuals) showed that depression appears as a risk factor for the diagnosis of DM with a prevalence of $20 \%$ to $30 \%$ (Fráguas et al., 2009). In a systematic review of the epidemiological aspects of depression, the prevalence of this mood 
disorder in DM patients ranged from $0 \%$ to $60.5 \%$ (Moreira et al., 2003). Independently of these mixed results, it is estimated that depression is two to four times higher in the DM population than in the healthy population (Silva, 2006). Moreover, the association between depressive symptoms and poor glycemic control (Guedes et al., 2016) and depression and diabetes complications (Nouwen et al., 2019) has been previously reported.

Adherence to long-term therapies for patients in developed countries is expected to achieve $50 \%$, whereas, for developing countries, it tends to exhibit a smaller percentage, given the lack of resources and inequality of access to health care (WHO, 2003). Some studies point to non-adherence rates ranging from $4 \%$ to $92 \%$, stating that these rates usually vary between $30 \%$ and $60 \%$ (Masek \& Janke, 1982). The WHO study "The COst of Diabetes in Europe - Type 2 [CODE-2]" states that $28 \%$ of patients pursuing treatment for DM achieve glucose control (WHO, 2003). In the United States, less than 2\% of DM adults carry out the ADA's highest recommended level of health care. These percentages are related to the fact that keeping DM under control requires more than simply taking medication (Costa et al., 2011; Fráguas et al., 2009; Guedes et al., 2016; Moreira et al., 2003; Silva, 2010; WHO, 2003). The literature reports that multiple factors influence a person's level of adherence to treatment. In addition to the precision associated with the administration of pharmacological therapies, patients are requested to engage in health promotion behaviors and, for most of them, to change their lifestyles. The centrality of the patient's role in self-administered health care management is a crucial topic. Adherence to treatment does not imply simply the scrupulous following of the medical regimen; it also entails engaging in several health-related behaviors, such as eating behaviors or physical activity (WHO, 2003). Indeed, DM implies the measurement of a wide range of intervening factors related to glycemic control. As the operationalization of these multiple factors is difficult, namely in terms of behavior, "results" are measured via what the evidence reports as predictors for care/practices for glycemic control - biochemical criteria provided by A1C testing (glycated hemoglobin testing). Therefore, A1C is used as a diagnostic and monitoring tool for glycemic control. These criteria can be influenced by multiple variables such as insulin sensitivity, an individual's physiological characteristics, and the efficiency of doctor-patient communication. Despite the limitations as mentioned above, the ADA recommends A1C as the best test to determine how well a patient's glycemia is under control.

As for A1C levels, studies conducted by the Diabetes Control and Complications Trial (DCCT) and by the United Kingdom Prospective Diabetes Study (UKPDS) have shown that the lower the A1C, the better the prognosis (International Diabetes Federation, 2017). Currently, the criterion of 'the lower the A1C levels, the better' is no longer widely accepted since values for A1C vary according to the patient, their age, and associated comorbidities. Therefore, the A1C recommended values by the ADA for young people without comorbidity is under $7 \%$, and under $8 \%$ for older individuals suffering from complications. When these scores are exceeded, the DM patient will be considered as not having the disease under control, and, from a clinical point of view, probably, glycemic control is not occurring.

The current study sought out to explore whether there were differences between T1DM and T2DM patients in terms of depressive symptoms, as well as the relationship between these symptoms and glycemic control, considering that depressive symptoms may influence the degree to which individuals engage in medical recommended procedures/behaviors. Moreover, the association of duration of the disease and depressive symptoms was also addressed. 


\section{Method}

\section{Participants}

This cross-sectional study included 347 individuals with a DM diagnosis (T1DM and T2DM) attending consultations at the Department of Endocrinology, Diabetes, and Metabolism of the Coimbra Hospital and University Centre (CHUC) and at the APDP - Diabetes Portugal (Portuguese Diabetes Patients Association). Inclusion criteria were age over 18 years old and a DM diagnosis for at least one year (the assisting doctor reported DM diagnosis). The current sample was a convenience sample.

\section{Instruments}

Sociodemographic questionnaire (SDQ). The SDQ included questions regarding age, sex, marital status, and years of education. Clinical data regarding A1C (metabolic control level) was also collected.

Beck Depression Inventory (BDI; Beck et al., 1961; Portuguese version by Vaz-Serra \& Pio-Abreu, 1973). The BDI is a widely used self-report measure of depressive symptoms composed of 21 groups of statements addressing affective, cognitive, motivational, delusional, physical, and functional (e.g., sleep pattern, weight loss, libido) symptoms. Data from the BDI validation study in the Portuguese population showed that scores between 0 and 9 indicate the absence of depression, between 10 and 20 slight depressive states, between 21 and 30 moderate levels of depression and over 30 severe depression (Vaz-Serra \& Pio-Abreu, 1973). In the current study, the BDI Cronbach alpha was of 89 .

\section{Procedures}

Participants' recruitment was carried out directly at the Department of Endocrinology, Diabetes, and Metabolism (CHUC) and the APDP, by healthcare professionals (physicians and psychologists) at the beginning of the consultation. Eighteen months was set for data collection. After receiving information regarding the study aims, the voluntary nature of their participation, as well as anonymity and confidentiality, participants gave their written informed consent and completed a set of self-report instruments (paper-pencil format). The Ethical Committee of the Coimbra Hospital and University Centre approved the study.

\section{Statistical analysis}

Data were analyzed using the IBM Software Statistical Package for Social Sciences (SPSS v.25). Independent samples $t$-tests were used for mean comparisons of continuous variables, and chi-square tests were used to compare frequencies. Odds ratios (ORs) with corresponding 95\% confidence intervals ( $\mathrm{Cls}$ ) for each level of each variable (in comparison with each variable's reference group) were analyzed. Pearson correlations were calculated as preliminary analysis for conducting multiple linear regression. Cohen's $d$ effect sizes were computed. Pearson correlations were used to explore the association between duration of DM diagnosis and depressive symptoms, as well as A1C levels (A1C $\leq 7 \%$ ). Assumptions for conducting statistical analyses were verified. 


\section{Results}

Table 1 presents the sociodemographic and clinical characteristics of participants. The two groups showed differences regarding age, with T2DM individuals being significantly older $(M=57.83 ; S D=11.40$; Cohen's $d=$ 1.55), with ages ranging from 18 to 81 years old. Regarding $A 1 C$, there were also significant differences between $\operatorname{T1DM}(t=2.40 ; p=.017 ;$ Cohen's $d=0.26)$. T1DM participants presented higher A1C scores $(M=8.58 ; S D=$ 1.47) when compared to T2DM $(M=8.19 ; S D=1.52)$.

\section{Table 1}

Sociodemographic and Clinical Characteristics of the Participants

\begin{tabular}{|c|c|c|c|c|c|c|}
\hline & \multicolumn{2}{|c|}{$\begin{array}{c}\text { T1DM } \\
(n=159)\end{array}$} & \multicolumn{2}{|c|}{$\begin{array}{c}\text { T2DM } \\
(n=188)\end{array}$} & \multirow[t]{2}{*}{$t(345)$} & \multirow[t]{2}{*}{$p$} \\
\hline & $M$ & $S D$ & $M$ & $S D$ & & \\
\hline Age & 38.80 & 13.10 & 57.83 & 11.40 & -14.47 & $<.001$ \\
\hline \multirow[t]{2}{*}{$\mathrm{A} 1 \mathrm{C}$} & 8.58 & 1.47 & 8.19 & 1.53 & 2.40 & .017 \\
\hline & $n$ & $\%$ & $n$ & $\%$ & $\chi^{2}$ & $p$ \\
\hline Gender & & & & & 2.19 & .139 \\
\hline Men & 83 & 52.2 & 113 & 60.1 & & \\
\hline Women & 76 & 47.8 & 75 & 39.9 & & \\
\hline Marital status & & & & & 61.00 & $<.001$ \\
\hline Single & 57 & 35.8 & 16 & 8.6 & & \\
\hline Married & 85 & 53.4 & 139 & 74.4 & & \\
\hline Divorced & 16 & 10.0 & 20 & 10.7 & & \\
\hline Widow & 1 & 0.6 & 12 & 6.4 & & \\
\hline Years of education & & & & & 50.64 & $<.001$ \\
\hline $1-4$ & 8 & 5.1 & 51 & 27.3 & & \\
\hline $5-6$ & 9 & 5.7 & 27 & 14.4 & & \\
\hline $7-9$ & 20 & 12.7 & 29 & 15.5 & & \\
\hline $10-12$ & 56 & 35.4 & 36 & 19.3 & & \\
\hline Higher Education & 65 & 41.1 & 44 & 23.5 & & \\
\hline
\end{tabular}

Note. $\mathrm{A} 1 \mathrm{C}=$ Glycated hemoglobin test; $\mathrm{T} 1 \mathrm{DM}=$ Type 1 diabetes mellitus; T2DM = Type 2 diabetes mellitus. Significant results are in bold.

No differences were found between T1DM and T2DM groups in the BDI total score $(t=-1.82 ; p=.070 ;$ Cohen's $d$ $=0.20$ ). However, a more detailed analysis regarding the BDI items, showed statistically significant differences between T1DM and T2DM regarding symptoms of work difficulty score ( $t=-4.74 ; p<.001$; Cohen's $d=0.52)$, insomnia score $(t=-2.21 ; p=.028$; Cohen's $d=0.24)$, fatigability score $(t=-2.40 ; p=.017$; Cohen's $d=0.26)$, weight loss score $(t=-2.08 ; p=.039$; Cohen's $d=0.22)$, and loss of libido score $(t=-4.76 ; p<.001$; Cohen's $d=0.51)$. For these symptoms mean scores were higher in T2DM (Table 2). No other differences were found between T1DM and T2DM concerning the other BDI symptoms. 


\section{Table 2}

T1DM and T2DM Comparisons Regarding Depressive Symptoms (BDI, Beck Depression Inventory)

\begin{tabular}{|c|c|c|c|c|c|}
\hline Items & & $M$ & $S D$ & $t$ & $p$ \\
\hline \multirow{2}{*}{ BDI-15 } & T1DM & 0.43 & 0.72 & \multirow{2}{*}{-4.74} & \multirow{2}{*}{$<.001$} \\
\hline & T2DM & 0.89 & 1.00 & & \\
\hline \multirow{2}{*}{ BDI-16 } & T1DM & 0.63 & 0.86 & \multirow{2}{*}{-2.21} & \multirow{2}{*}{.028} \\
\hline & T2DM & 0.86 & 1.04 & & \\
\hline \multirow{2}{*}{ BDI-17 } & T1DM & 0.65 & 0.62 & \multirow{2}{*}{-2.40} & \multirow{2}{*}{.017} \\
\hline & T2DM & 0.81 & 0.62 & & \\
\hline \multirow{2}{*}{ BDI-19 } & T1DM & 0.31 & 0.69 & \multirow{2}{*}{-2.08} & \multirow{2}{*}{.039} \\
\hline & T2DM & 0.49 & 0.90 & & \\
\hline \multirow{2}{*}{ BDI-21 } & T1DM & 0.50 & 0.84 & \multirow{2}{*}{-4.76} & \multirow{2}{*}{$<.001$} \\
\hline & T2DM & 0.99 & 1.04 & & \\
\hline
\end{tabular}

Note. T1DM = Type 1 diabetes mellitus; T2DM = Type 2 diabetes mellitus.

The association between depressive symptoms and glycemic control in T1DM patients was statistically significant $\left(\chi_{2}=5.86 ; p=.015\right)$. T1DM patients showing no depressive symptoms show 5.4 times more glycemic control than those participants presenting depressive symptoms $(O R=5.4 ; I C 95 \%=1.20-24.21)$. As for T2DM, depressive symptoms were also associated with glycemic control $\left(\chi_{2}=6.58 ; p=.010\right)$. T2DM participants showing depressive symptoms exhibit 2.5 times more glycemic control than those with T2DM showing no depressive symptoms (OR $=2.5 ;$ IC95\% $=1.251-5.053)$. Associations between sex, age, marital status, years of education and glycemic control were also explored as preliminary analyses for conducting a multiple linear regression. Given that no significant associations were found $(p>.05)$ the regression analysis was not performed.

Finally, when considering the association of duration of the disease and depressive symptoms, no significant correlations were found for either T1DM $\left(r=-0.07 ; p=.650 ; R_{2}=0.49 \%\right)$, or T2DM $\left(r=-0.02 ; p=.826 ; R_{2}=0.04 \%\right)$. The same pattern was found for the correlation between the duration of DM diagnosis and glycemic control for $\operatorname{T1DM}\left(r=-0.17 ; p=.236 ; R_{2}=2.89 \%\right)$, or T2DM $\left(r=0.08 ; p=.440 ; R_{2}=0.64 \%\right)$.

\section{Discussion}

DM is a clinical condition with specific characteristics, even when compared with other chronic pathologies. Whereas T1DM implies that a patient will have earlier contact with the disease and its therapeutic demands, T2DM obliges individuals to undergo significant changes regarding both pharmacological treatment and lifestyle. These subsequent changes in behavior, such as eating habits and physical activity levels, may lead to emotional reactivity. Thus, the emotional impact when faced with a DM diagnosis and its treatment plan must be taken into account when attempting to achieve a more holistic approach. Common emotional reactions are anger, resentment, and depression, independently from the etiology and age group, leading to significant psychosocial changes (Santos Filho et al., 2008). Indeed, the relationship between depression and chronic diseases (Birk et al., 2019), and depression and specifically DM has been frequently acknowledged in the literature (Cox \& GonderFrederick, 1992; Fráguas et al., 2009; Góis, 2013; Saraiva, 2014). 
In the current study, when comparing the sociodemographic characteristics of participants presenting T1DM and T2DM, differences were found in terms of age, marital status, and years of education. These differences were somehow expected, given that the incidence of T2DM is higher for older age groups. Regarding the comparison of $A 1 C$, differences were also found between the groups, with T2DM patients showing more favorable glycemic control scores. This finding may be attributable to the fact that control of T2DM is easier to establish as the pancreas is still able to produce insulin; this not being the case in T1DM.

Regarding the association between glycemic control and depressive symptoms in T1DM and T2DM, a significant relationship was found in both groups, which is in accordance to what has been reported in the literature (Egbuonu et al., 2019; Park et al., 2004; Picozzi \& DeLuca, 2019; Santos et al., 2013). Nevertheless, in other studies, depressive symptoms and glycemic control did not show a clinically significant association (Braz et al., 2012; Fisher et al., 2007). Similarly, emotional factors such as depression were not associated in a significant way with DM glycemic control (Ramos \& Ferreira, 2011; Silva et al., 2005). Although studies addressing the relationship between depressive symptoms and glycemic control in DM patients have produced mixed results, in the current study, differences were found between T1DM and T2DM patients. While these clinical conditions are manifestly different, the glycemic control criteria used were the same.

Moreover, current study results were similar to the ones found in other studies for T1DM (Tovar et al., 2015); for T2DM, they were in the opposite direction (Mansori et al., 2019). In T2DM patients, the occurrence of depressive symptoms was associated with greater glycemic control. Nevertheless, some aspects have to be considered in these findings' interpretation. First, in the current sample, depressive symptoms results showed subclinical significance as opposed to the ones identified in previous studies (Braz et al., 2012). More recently, Shrestha et al. (2020) conducted a systematic review and found inconsistent results regarding the association between subthreshold depression and self-care behaviors in T2DM. Also, it is relevant to note the fact that the significant differences between the groups are fundamentally somatic. Considering the symptoms, "work difficulty," "insomnia," "fatigability," "weight loss," and "loss of libido" it is hypothesized that these might well correspond to the physical consequences of DM as opposed to depressive symptoms. Some authors consider that the relationship between depression and DM may be related to other biological changes, namely high cortisol levels and changes in norepinephrine and serotonin levels (Talbot et al., 1999; Griffiths \& Lustman, 1997).

Consequently, the relationship between depressive symptoms and glycemic control found in T2DM patients may not express this relationship. It may result from the need to adapt to lifestyle changes and the physical consequences of DM. These lifestyle changes aiming for the improvement of metabolic control may have consequences, and these can be confounded with the previously mentioned BDI symptoms. Thom et al. (2019), in their literature review, suggest that major depression may be seen as a systemic illness given that its pathophysiology overlaps with other systemic medical conditions.

Furthermore, these results may also be interpreted from an evolutionary perspective. Mood plays a mediating role regarding the mobilization of survival strategies, and negative mood states may lead to the activation of psycho-emotional resources when facing demanding tasks (Rottenberg, 2014). Therefore, it is hypothesized that T2DM patients showing higher levels of depressive symptoms may be prone to pursue therapy and consequently improve their glycemic control. The relationship between DM and depression can be explained by disease management factors (Mezuk et al., 2013), and the identification and treatment of depression in DM patients are also highly recommended (Khan et al., 2019; Owens-Gary et al., 2019). 
The BDI is considered as an adequate instrument for assessing depression in T1DM and T2DM patients (Lustman et al., 1997). However, it is a general instrument and may not address specificities inherent to DM. Furthermore, the BDI is a self-report measure, and this can be a limitation given that more detailed information can be obtained via a structured interview. In this context, the development of an assessment instrument able to capture the emotional impact of DM specific features would be relevant in the future. Other limitations to be acknowledged are the study's cross-sectional design that does not allow causal conclusions to be drawn and the sample size.

Additionally, the study examines different size groups of DM patients who have sought support at the APDP, and it can be theorized that the contact with a patients' association may contribute to being better informed and more integrated and, consequently, presenting lower levels of depressive symptomatology. There are therapeutic factors that operate as change promoters in group contexts, as would be the case of patients' associations that support individuals with the disease (Yalom \& Leszcz, 2005). Nevertheless, additional research is needed to clarify the role of being in touch with a patients' association in depressive symptoms and glycemic control.

\section{Conclusion}

To sum, it is important to highlight the distinction between depressive symptoms and the physical consequences inherent to T2DM treatment, given that they may be confounded.

Acknowledgments | Agradecimentos: The authors would like to thank all participants and professionals who cooperated in data collection.

Conflict of interest | Conflito de interesse: The Authors declare that there is no conflict of interest.

Funding sources | Fontes de financiamento: None | nenhuma.

Contributes: IMC: Study design; Preparation of measures and writing of the protocol; Recruitment of participants; Statistical analysis; Supervision of the writing of the manuscript and approval of the final manuscript. FD: Bibliographic research; Literature revision; Statistical analysis; Writing of the manuscript. VR: Final review and approval of the manuscript. AG: Statistical analysis; Writing, final revision, and approval of the manuscript.

\section{References}

Beck, A., Ward, C., Mendelson, M., Mock, J., \& Erbaugh, J. (1961). An inventory for measuring depression. Archives of General Psychiatry, 4(6), 561-571. https://doi.org/10.1001/archpsyc.1961.01710120031004

Birk, J. L., Kronish, I. M., Moise, N., Falzon, L., Yoon, S., \& Davidson, K. W. (2019). Depression and multimorbidity: Considering temporal characteristics of the associations between depression and multiple chronic diseases. Health Psychology, 38(9), 802-811. https://doi.org/10.1037/hea0000737

Braz, J. M., Silva, R.M., Góis, C. F. L., Braz, T. M., Santos, V., \& Silva, L. A. S. M. (2012). Sintomas depressivos e adesão ao tratamento entre pessoas com diabetes mellitus tipo 2 [Depressive symptoms and adherence to treatment among people with type 2 diabetes mellitus]. Revista da Rede de Enfermagem do Nordeste, 13, 1092-1099. http://www.periodicos.ufc.br/rene/article/view/4108

Chireh, B., Li, M., \& D'Arcy, C. (2019). Diabetes increases the risk of depression: A systematic review, meta-analysis and estimates of population attributable fractions based on prospective studies. Preventive Medicine Reports, 14, 100822. https://doi.org/10.1016/j.pmedr.2019.100822 
Costa, J. A., Balga, R. S. M., Alfenas, R. C. G., \& Cotta, R. M. M. (2011). Promoção da saúde e diabetes: discutindo a adesão e a motivação de indivíduos diabéticos participantes de programas de saúde [Health promotion and diabetes: Discussing the adherence and motivation of diabetics that participate in health programs]. Ciência \& Saúde Coletiva, 16(3), 2001-2009. https://doi.org/10.1590/S1413-81232011000300034

Cox, D. J., \& Gonder-Frederick, L. (1992). Major developments in behavioral diabetes research. Journal of Consulting Psychology, 60(4), 628-638. https://doi.org/10.1037//0022-006x.60.4.628

Egbuonu, I., Trief, P. M., Roe, C., \& Weinstock, R. S. (2019). Glycemic outcomes related to depression in adults with type 1 diabetes. Journal of Health Psychology. Advance online publication. https://doi.org/10.1177/1359105319877298

Fráguas, R., Soares, S. M. S. R., \& Bronstaein, M. D. (2009). Depressão e diabetes mellitus [Depression and diabetes mellitus]. Revista de Psiquiatria Clínica, 36(3), 93-99. https://doi.org/10.1590/S0101-60832009000900005

Fisher, L., Skaff, M., Mullan, J., Arean, P., Mohr, D., Masharani, U., Glasgow, R., \& Laurencin, G. (2007). Clinical depression versus distress among patients with type 2 diabetes: Not just a question of semantics. Diabetes Care, 30(3), 542548. https://doi.org/10.2337/dc06-1614

Góis, C. J. F. C. (2013). Estados depressivos em diabetes tipo 2 [Doctoral dissertation, Universidade de Lisboa]. Repositório da Universidade de Lisboa. https://repositorio.ul.pt/handle/10451/8976

Gonzalez, J. S., Safren, S. A., Cagliero, E., Wexler, D. J., Delahanty, L., Wittenberg, E., Blais, M. A., Meigs, J. B., \& Grant, R. W. (2007). Depression, self-care, and medication adherence in type 2 diabetes: Relationships across the full range of symptom severity. Diabetes Care, 30(9), 2222-2227. https://doi.org/10.2337/dc07-0158

Griffiths, L. S., \& Lustman, P. J. (1997). Depression in women with diabetes. Diabetes Spectrum, 10, $216-223$. http://journal.diabetes.org/diabetesspectrum/97v10n3/pg216.htm

Guedes, M. F. S., Sales-Peres, S. H. C., Negrato, C. A., Lauris, J. R. P., \& Sá, L. M. (2016). Estilo de vida em pacientes portadores de diabetes mellitus tipo 1: uma revisão sistemática [Lifestyle of patients with diabetes mellitus type 1: A systematic review]. Ciência \& Saúde Coletiva, 21(4), 1197-1206. https://doi.org/10.1590/141381232015214.20242015

International Diabetes Federation. (2020). IDF diabetes atlas (9th ed.) [e-book]. www.diabetesatlas.org

Kahanovitz, L., Sluss, P. M., \& Russell, S. J. (2017). Type 1 Diabetes - A clinical perspective. Point of Care, 16(1), 37-40. https://doi.org/10.1097/POC.0000000000000125

Khan, Z. D., Lutale, J., \& Moledina, S. M. (2019). Prevalence of depression and associated factors among diabetic patients in an outpatient diabetes clinic. Psychiatry Journal, Article 2083196. https://doi.org/10.1155/2019/2083196

Lustman, P. J., Clouse, R. E., Griffith, L. S., Carney, R. M., \& Freedland, K. E. (1997). Screening for depression in diabetes using the Beck Depression Inventory. Psychosomatic Medicine, 59(1), 24-31. https://doi.org/10.1097/00006842199701000-00004

Mansori, K., Shiravand, N., Shadmani, F. K., Moradi, Y., Allahmoradi, M., Ranjbaran, M., Ahmadi, S., Farahani, A., Samii, K., \& Valipour, M. (2019). Association between depression with glycemic control and its complications in type 2 diabetes. Diabetes \& Metabolic Syndrome: Clinical Research \& Reviews, 13(2), 1555-1560. https://doi.org/10.1016/j.dsx.2019.02.010

Masek, B. J., \& Janke, W. R. (1982). Therapeutic adherence. In D. C. Russo \& J. W. Varni (Eds.), Behavioral pediatrics: Research and practice (pp. 375-395). Plenum Press.

Mezuk, B., Johnson-Lawrence, V., Lee, H., Rafferty, J. A., Abdou, C. M., Uzogara, E. E., \& Jackson, J. S. (2013). Ignorance is a bliss? Depression, antidepressants, and diagnosis of prediabetes and type 2 diabetes. Health Psychology, 32(3), 254-263. https://doi.org/10.1037/a0029014

Moreira, R. O., Papelbau, M., Appolinario, J. C., Matos, A. G., Coutinho, W. F., Meirelles, M., Ellinger, V. C. M., \& Zagury, L. (2003). Diabetes Mellitus e depressão: uma revisão sistemática [Diabetes mellitus and depression: A systematic review]. Arquivo Brasileiro de Endocrinologia e Metabolismo, 47(1), 19-29. https://doi.org/10.1590/S000427302003000100005

Nouwen, A., Adriaanse, M. C., van Dam, K., Iversen, M. M., Viechtbauer, W., Peyrot, M., Caramlau, I., Kokoszka, A., Kanc, K., de Groot, M., Nefs, G., Pouwer, F., \& the European Depression in Diabetes (EDID) Research Consortium. (2019). Longitudinal associations between depression and diabetes complications: A systematic review and meta-analysis. Diabetic Medicine, 36(12), 1562-1572. https://doi.org/10.1111/dme.14054

Owens-Gary, M. D., Zhang, X., Jawanda, S., Bullard, K. M., Allweiss, P., \& Smith, B. D. (2019). The importance of addressing depression and diabetes distress in adults with type 2 diabetes. Journal of General Internal Medicine, 34(2), 320-324. https://doi.org/10.1007/s11606-018-4705-2 
Park, H., Hong, Y., Lee, H., \& Sung, Y. (2004). Individuals with type 2 diabetes and depressive symptoms exhibited lower adherence with self-care. Journal of Clinical Epidemiology, 57(9), 978-984. https://doi.org/10.1016/j.jclinepi.2004.01.015

Picozzi, A., \& Deluca, F. (2019). Depression and glycemic control in adolescent diabetics: Evaluating possible association between depression and hemoglobin A1c. Public Health, 170, 32-37. https://doi.org/10.1016/j.puhe.2019.02.005

Ramos, L., \& Ferreira, E. A. P. (2011). Emotional factors, life quality and adhesion of treatment in adult with type 2 diabetes. Journal of Human Growth and Development, 21(3), 867-877. http://pepsic.bvsalud. scielo.php?script=sci_arttext\&pid=S0104-12822011000300013\&lng=pt\&nrm=iso\&tlng=en

Rottenberg, J. (2014). The depths: The evolutionary origins of the depression epidemic. Basic Books.

Santos Filho, C. V., Rodrigues, W. H. C., \& Santos, R. B. (2008). Papéis de autocuidado: subsídios para enfermagem diante das reações emocionais dos portadores [Self-care roles - Subsidy to the nursing before the emotional reactions of the diabetes Mellitus carriers]. Escola Anna Nery Revista de Enfermagem, 12(1), $125-129$. https://doi.org/10.1590/S1414-81452008000100019

Santos, F. R. M., Bernardo, V., Gabbay, M. A. L., Dib, S. A., \& Sigulem, D. (2013). The impact of knowledge about diabetes, resilience and depression on glycemic control: A cross-sectional study among adolescents and young adults with type 1 diabetes. Diabetology \& Metabolic Syndrome, 5(55), 1-5. https://doi.org/10.1186/1758-5996-5-55

Saraiva, C. B. (2014). Um guia clínico nos cuidados de saúde primários [A clinical guide for primary healthcare]. Lidel.

Shrestha, M., Ng, A., Al-Ghareeb, A., Alenazi, F., \& Gray, R. (2020). Association between subthreshold depression and self-care behaviors in people with type 2 diabetes: A systematic review of observational studies. Systematic Reviews, 9(45), 1-9. https://doi.org/10.1186/s13643-020-01302-z

Silva, I. (2006). Psicologia da diabetes [Diabetes psychology]. Quarteto Editora.

Silva, I. (2010). Psicologia da diabetes [Diabetes psychology]. Placebo, Editora Lda.

Silva, I., Cardoso, H., \& Pais-Ribeiro, L. (2005). Variáveis psicológicas associadas à adesão ao tratamento da diabetes mellitus [Psychological variables associated to treatment adherence in diabetes mellitus]. Psicologia, 18(2), 159171. https://doi.org/10.17575/rpsicol.v18i2.434

Son, J., Nyklíček, I., Pop, V. J. M., \& Pouwer, F. (2011). Testing the effectiveness of a mindfulness-based intervention to reduce emotional distress in outpatients with diabetes (DiaMind): Design of a randomized controlled trial. BMC Public Health, 11(131), 2-11. https://doi.org/10.1186/1471-2458-11-131

Talbot, F., Nouwen, A., Gingras, J., Bélanger, A., \& Audet, J. (1999). Relations of diabetes intrusiveness and personal control to symptoms of depression among adults with diabetes. Health Psychology, 18(5), $537-542$. https://doi.org/10.1037/0278-6133.18.5.537

Thom, R., Silbersweig, D. A., \& Boland, R. J. (2019). Major depressive disorder in medical illness: A review of assessment, prevalence, and treatment options. Psychosomatic Medicine, 81(3), $246-255$. https://doi.org/10.1097/PSY.0000000000000678

Tovar, E., Rayens, M. K., Gokun, Y., \& Clark, M. (2015). Mediators of adherence among adults with comorbid diabetes and depression: The role of self-efficacy and social support. Journal of Health Psychology, 20(11), $1405-1415$. https://doi.org/10.1177/1359105313512514

Vaz-Serra, A., \& Pio-Abreu, J. L. (1973). Aferição dos quadros clínicos depressivos. I - Ensaio de aplicação do "inventário depressivo de Beck" a uma amostra portuguesa de doentes deprimidos [Assessment of depressive clinical conditions. I - Study of the "Beck's Depressive Inventory" in a Portuguese sample of depressed patients]. Coimbra Médica, XX, 623-644.

Word Health Organization. (2011). Use of glycated haemoglobin [e-book]. http://www.who.int/cardiovascular_diseases/report-hba1c_2011_edited.pdf

Word Health Organization. (2016). Global report on diabetes. https://www.who.int/diabetes/global-report/en/

Word Health Organization. (2003). Innovative care for chronic conditions: Action structural components - world report. https://www.who.int/chp/knowledge/publications/icccreport/en/

Yalom, I. D., \& Leszcz, M. (2005). The theory and practice of group psychotherapy. Basic Books. 